\title{
Professionalism by proxy: a case for the formal regulation of dental assistants in Australia
}

\author{
A. C. L. Holden, ${ }^{* 1}$ G. Jean, ${ }^{2}$ M.Tennant ${ }^{2}$ and H. Spallek ${ }^{1}$
}

Key points

Delivers a cross-jurisdictional discussion on dental assistant/nurse workforce development.
Explains the need for dental assistant regulation from a perspective of public safety.
Details the professional power relationships within the dental profession from several different jurisdictions.

Dental assistants are the most numerous member of the dental team in Australia, responsible for many clinical and non-clinical duties. Despite this, dental assistants are not registered and regulated in the same manner as their clinical colleagues within the dental profession. In this article, the authors argue that this is an unacceptable situation within the Australian dental context. In the examination of events within the profession both within Australia and overseas, it becomes apparent that this is an untenable position with regards to promoting the safety of the public. The current stance towards dental assistants is often perpetuated by a dental profession whose motives would not seem to be free from issues of professional dominance. Dental assistants may also be an essential division of the dental profession in providing culturally competent, economically viable and sustainable oral healthcare to those communities that are traditionally difficult to access.

\section{Introduction}

Since the professionalisation of dentistry as a protected and regulated entity (around the beginning to the middle of the last century in many countries), the profession has blossomed to include a variety of oral health practitioners who provide clinical care to patients. Within Australia, there are five distinct divisions of dental practitioner who are formally regulated; dentists, prosthetists, oral health therapists, dental therapists and dental hygienists. These dental professionals are registered under the National Registration and Accreditation Scheme (NRAS) pursuant to the enactment of the National Law in each state and territory. ${ }^{1-7}$

The University of Sydney School of Dentistry, Faculty of Medicine and Health, 2-6 Chalmers Street, Surry Hills, NSW 2010, Australia; ${ }^{2}$ International Research Collaborative

- Oral Health and Equity, School of Human Sciences,

The University of Western Australia, 35 Stirling Highway,

Crawley, WA 6009, Australia

${ }^{*}$ Correspondence to: Alexander Holden

Email: alexander.holden@sydney.edu.au

Refereed Paper.

Accepted 4 June 2018

Published online 7 September 2018

DOI: $10.1038 /$ sj.bdj.2018.759
Under the NRAS, there are fifteen National Boards that regulate the allopathic health professions, as well as complementary health professions such as Chinese medicine practitioners, chiropractors and osteopaths. In this article, the authors argue that a sixth division of dental practitioner should be established in Australia that regulates the most numerous group of professionals working in dentistry; the dental assistant. Statistics from 2015 suggest the number of dental assistants in Australia to be just under eighteen and a half thousand, with this number rising to over nineteen thousand by $2020 .{ }^{8}$ Through analysis of other jurisdictions, the evidence-base relating to the provision of clinical treatment and the relevant framework of regulation in Australia, the authors will argue that the current lack of formal registration and specific regulation of dental assistants is inappropriate and in need of reconsideration.

Due to there being no requirement for registration with the Dental Board of Australia (DBA), there is no current standard that must be met before an individual may act in the capacity of a dental assistant. Registered dental practitioners must satisfy the requirements of registration for each division set out by the DBA. As well as meeting the educational requirements, this also means that registrants: must disclose their criminal history; demonstrate proficiency in the English language; commit to having appropriate indemnity arrangements in place; must demonstrate recency of practice; must declare they are aware of their disease status for blood-borne viruses; declare there is no impairment to their practice and; commit to compliance with continued professional development requirements. There is no professional regulatory requirement upon dental assistants to demonstrate meeting any of these requirements before commencing working. There is also no formal requirement for dental assistants to undergo a period of structured training with an accredited body. Dental assistants are essential members of the dental team whose responsibilities are varied. Many of these include direct patient contact in a clinical situation, management of sensitive health data and undertaking infection control procedures. Many of the components that contribute to the establishment of an individual being a fit and proper person to be registered as a dental practitioner are pertinent to practising as a dental assistant. 


\section{Scope of practice}

The DBA has published a scope of practice for each practitioner division it regulates. There is no equivalent scope of practice that relates to the practice of a dental assistant. This may give rise to confusion over the status of the dental assistant as to where the limits of their duties within clinical practice might lie. The only regulated area of the dental assistant's role relates to the taking of intra-oral and extra-oral radiographs under prescription from another practitioner; this requires a dental assistant to hold a licence from the Environmental Protection Agency (EPA) or similar government radiation regulator. Dental assistants effectively have equivalency with members of the public with regard to the extent of their duties. The National Law sets out protected acts which may only be carried out by a dental or medical practitioner in section 121 (Box 1).

From these provisions, it would appear that dental assistants must assess their scope of practice on the basis of what might conflict with the restricted dental acts and define their scope by reverse logic. The restricted dental acts are comprehensive, but not specific. This leads to grey areas of uncertainty. A dispute between the Liquor Hospitality and Miscellaneous Union, Queensland Branch (LHMU) and the Queensland Branch of the Australian Dental Association (ADAQ) regarding the wages paid to dental assistants ${ }^{9}$ noted the ambiguity in the role of the dental assistant.

During this dispute, the ADAQ posited that dental assistants with training at certificate levels 3 and 4 'perform extended duties under the direction of a dentist, including but not limited to treatment coordination, taking impressions, pouring up and trimming diagnostic models, making trays, making mouthguards, placing matrix bands and rubber dam apparatus.' The LHMU disagreed with this scope, stating that the placing of matrix bands and rubber dam apparatus; 'was probably illegal.' The Commission heard the witness testimony of a variety of experts, but conceded that this was based upon opinion-based interpretation of the then-in-force dental act which at the time, had been recently amended in $2004 .{ }^{10}$ The then-president of ADAQ, stated that the matter would only likely be resolved, as to whether a dental assistant would be breaking the law in performing such duties, by a court following an assistant being formally charged. The legislation has now changed that dictates the scope of those acts within dentistry which are restricted. However, the situation regarding lack of clarity of dental assistant scope of practice persists. Under the current incarnation of the restricted dental acts, the legislative provisions would not exclude a dental assistant from taking impressions for diagnostic purposes. Should this procedure be part of the process of constructing a dental device, such as a denture, mouthguard or crown, this would then constitute a restricted dental act under section 121(d) of the national law. The current legislation makes no allowance for extendedduties dental assistants; assistants may take courses teaching them impression techniques, but this is not supported explicitly within the national law.

It is an unreasonable position to support the placement of the dental assistant, who may or may not have had formal training, into a situation where he or she may have no authoritative guide as to their legitimate scope of practice. If those at the pinnacle of the dental profession can only posture, not confirm, what may or may not be acceptable, this speaks to a professional situation that would not be tolerated in the practice of other clinical members of the dental team. Within the airline industry, each member of the crew has exact duties and responsibilities in aircraft safety and security. Similarly, the safeguarding of patients in dental practice is a team-responsibility and is only effective if each member is clearly aware of their role and accountability.

\section{Box 1 Restricted dental acts}

National Law - Definition of the restricted dental acts as given by section 121

'restricted dental act' means any of the following acts:

(a) performing any irreversible procedure on the human teeth or jaw or associated structures

(b) correcting malpositions of the human teeth or jaw or associated structures

(c) fitting or intra-orally adjusting artificial teeth or corrective or restorative dental appliances for a person

(d) performing any irreversible procedure on, or the giving of any treatment or advice to, a person that is preparatory to or for the purpose of fitting, inserting, adjusting, fixing, constructing, repairing or renewing artificial dentures or a restorative dental appliance.

\section{The current regulatory framework in Australia applicable to dental assistants}

Dental assistants are registered with the dental regulators in a variety of other jurisdictions including the United Kingdom, many parts of Europe, South Africa and most provinces and territories of Canada (Quebec and Ontario currently do not have registration for dental assistants). Often within these jurisdictions they are known as dental nurses. As will be explored, the process of dental assistant professionalisation has faced considerable resistance in some jurisdictions where it has been proposed and implemented. In the same manner as dental therapists have been used within an expanded scope of practice, dental assistants have also been utilised in the UK to provide preventative dental advice and treatment. ${ }^{11}$ It is possible that given the NRAS's objective of increasing the healthcare workforce's accessibility and flexibility, the role carried out by extended duties dental assistants/nurses in other jurisdictions may be carried out by other health professionals. So far, this has not been widely considered or trialled within Australia. This has mainly occurred in Aboriginal communities where Aboriginal Health Workers have been engaged in oral health promotion strategies involving, at times, the application of fluoride varnish. ${ }^{12}$

Dental assistants are not registered with the DBA but are regulated indirectly by 'negative licensing'13 provided for by the National Code of Conduct for healthcare workers. ${ }^{14}$ This code or the progenitors to this code are currently in force in New South Wales, South Australia, Queensland and Victoria. The COAG Health Council (CHC) has directed that each state and territory is responsible for the implementation and progression of the Code of Conduct. The purpose of the Code of Conduct is given to be: ' $(\mathrm{T}) \mathrm{o}$ protect the public by setting minimum standards of conduct and practice for all unregistered health care workers who provide a health service. ${ }^{13}$ The code does not speak to the scope of practice of dental assistants. The drafting of the National Code is considerably comprehensive and there are many similarities between the National Code and the NRAS. Neither is proactive, and both rely on a complaint being received before any investigation and disciplinary measures are taken. Both include a provision for removing 'unfit persons' from working in healthcare, and will publish 
prohibition orders and disciplinary findings on public registers. There are penalties for breaches of orders and legal liability under the civil liability act remains unaffected. The perceived need for the introduction of the National Code of Conduct is testament to the fact that presently not all instances where the public have been exposed to significant harm are adequately addressed by the NRAS. The dilemma is therefore, when should a profession be registered under the NRAS or will the National Code provide a similar level of protection for the public against malpractice by divisions of health workers not included in the NRAS?

In the UK, where dental assistants (known as dental nurses) are registered with the General Dental Council (GDC), in 2016, there were 66 cases relating to dental nurses considered by the Interim Orders Committee (IOC).$^{15}$ The IOC manages serious complaints against registrants and makes decisions as to whether it is appropriate to immediately prevent or place limits upon a dental professional's practice until their case is heard. A recent case found dental nurse, Sally Hague, indefinitely suspended resultant from her part in poor infection control in a practice in Nottingham (UK) which resulted in what has been described as the "biggest recall in NHS history. ${ }^{16}$ In this case more than 22,000 patients were recalled and invited for blood testing for blood-borne viruses following on from the re-use of disposable equipment, poor hand-washing practice and failing to change gloves in-between patients. The General Dental Council stated that her; 'conduct was serious and demonstrated a complete disregard for all infection control procedures. ${ }^{17}$ In contrast, when similar circumstances involving poor infection-control practice occurred in Sydney in $2015,{ }^{18}$ there were no complaints made against any of the dental assistants working in the practices involved. This is despite it being common knowledge that while registered dental professions may have overarching responsibility for infection control, it is dental assistants who carry out the majority, if not all, of the daily duties to accomplish infection control.

In NSW, the Code of Conduct produced by the Health Care Complaints Commission for un-registered health professionals commenced in 2008. Since this time there have been no documented cases brought against dental assistants. It is clear, that the nonspecificity of the Code is insufficient to manage the nuances of dental assistant practice. If we want to comprehensively protect the public, dental assistants should be registered with the Dental Board of Australia as a distinct professional division following the lead of other jurisdictions. The dental profession has so far rejected the regulation of dental assistant practice. A former President of the Australian Dental Association stated in a letter that there was no need for further regulation in the form of the National Safety and Quality Care Standards in dental practices as: 'The fact that registered practitioners operate in the accredited practice should sufficiently indicate that appropriate safety standards are being met without having to be further subjected to the clerical burden of demonstrating compliance with the Commission's Standards. ${ }^{19}$ This statement is dismissive of the fact that the majority of those who work in a dental practice, either as clerical staff or as dental assistants (often as both) are neither required to undergo any formal training or qualification, nor are they required to be registered. Even if the current codes of conduct that exist for un-registered health workers are deemed fit for purpose for dental assistant regulation, they are not universally in force; Western Australia, the Northern Territory, Tasmania and the Australian Capital Territory currently do not have codes pertaining to the practice of unregistered health practitioners. The profession needs to recognise this significant deficiency and lack of uniformity in dental workforce regulation.
A key difference between inclusion under the National Code of Conduct and the NRAS is that the former does not require formal training. If it is accepted that dental nurses not maintaining contemporary knowledge of infection control protocols and failing to operate at a competent standard can pose a significant risk to the public by exposing patients to the risk of HCAIs then it must be in the public interest to advocate for the development of nationally accredited education qualification as the basis of a registration standard. It would also be in the interests of the dental assisting profession to have a formal level of compulsory training to prepare them for competent practice.

\section{To register or not to register?}

The 2014, review of the NRAS ${ }^{20}$ recognised widespread misunderstanding relating to the reasons for some professions being excluded from the NRAS and why others were included. The primary purpose of registration of health professionals is to protect the public. The potential for patients to be harmed by unskilled, unqualified, and/or impaired healthcare workers warrants a formal legislated process to oversee the validation of appropriate levels of training and competence and provide a pathway for managing patient complaints about individual practitioner performance. Prior to the introduction of the NRAS, this process was managed on a state by state basis by more than 50 registration boards. There were differences in the number of 'professions' registered in each state, and a lack of uniformity of accreditation standards that restricted the rights of some healthcare workers to practice outside their initial accrediting jurisdiction.

The criteria against which new professions seeking inclusion under the NRAS are assessed (Box 2) is based on a risk-benefit analysis and is derived from the Council of Australian Governments. ${ }^{21}$ The key determinant is

\title{
Box 2 Criteria for assessing the need for the statutory regulation of unregulated health occupations
}

\author{
Assessment criteria for need of statutory regulation \\ 1. Is it appropriate for Health Ministers to exercise responsibility for regulating the occupation in question, or does the occupation more appropriately fall within the \\ domain of another ministry? \\ 2. Do the activities of the occupation pose a significant risk of harm to the health and safety of the public? \\ 3. Do existing regulatory or other mechanisms fail to address health and safety issues? \\ 4. Is regulation possible to implement for the occupation in question? \\ 5. Is regulation practical to implement for the occupation in question? \\ 6. 6 . Do the benefits to the public of regulation clearly outweigh the potential negative impact of such regulation?
}


'significant risk'; If this level of risk can be identified, and it is possible to minimise the risk by setting a registration standard that includes a minimum level of training to an agreed accredited standard, the argument for inclusion in the NRAS is compelling. In the period 2015-2016, it is estimated that $48 \%$ of Australians aged 15 and over saw a dentist at least once in the preceding 12-month period. ${ }^{22}$ All these patients relied upon the proper application of infection control mechanisms by dental assistants.

\section{Experiences from other jurisdictions}

Several jurisdictions have already begun formal and direct regulation of dental assistants, such as the UK. Others have recently had discussions relating to whether a formal process of regulation should begin, such as Ontario and South Africa.

\section{Ontario}

In 2007, the then-Minister for Health and Long-Term Care asked the Health Professions Regulatory Advisory Council (HPRAC) to consider whether dental assistants should be regulated under the relevant legislation ${ }^{23}$ and if so, what the appropriate scope of practice, controlled acts and protected titles would be for the profession. The date for the HPRAC's final advice on the regulation of dental assistants and other health professions (diagnostic sonographers, paramedics and emergency medical attendants) to be delivered was 31December 2013. ${ }^{24}$

The Ontario Dental Assistants Association (ODAA) made an initial application ${ }^{25}$ for self-regulation which was then responded to by stakeholders. The ODAA's application placed the protection of the public as their primary argument for self-regulation, with seven secondary areas: professional autonomy; educational requirements for entry to practice; body of knowledge and scope of practice; economic impact of regulation; regulatory mechanisms; leadership ability to favour the public interest and membership support and willingness of the profession to be regulated and; health system impact. Much of the ODAA's proposal centred on the dental assistant's role in ensuring high levels of infection control. The ODAA's application gained support from many dental professional groups who responded. Both the College of Dental Hygienists of Ontario, who stated that the ODAA's argument was compelling and the Denturist Association of Ontario who believed that self-regulation of dental assistants was in the public interest, lent their support to the ODAA's application. ${ }^{26}$

The Ontario Dental Association (ODA) was less than supportive of the ODAA's proposal in its submission. The ODA stated that the activities of a dental assistant were low risk and therefore the regulation of assistants as self-regulating professionals was inappropriate under the Regulated Health Professions Act 1991. The ODA went further on this point and argued that the ODAA had failed to demonstrate that the status quo was a risk to the public. One of the main justifications the ODA used in its argument was that dental assistants are largely supervised in their roles by other, regulated dental professionals and therefore further regulation was unnecessary. It is also of note that the ODA objected strongly to the insinuation that it perceived the ODAA had made in its proposal, that dental assistants are the main members of the dental team concerned with cross-infection-control. The ODA submission quotes the Royal College of Dental Surgeons of Ontario's (RCDSO) infection-control guidelines which state that dentists have an obligation and responsibility to ensure that staff are adequately equipped and trained to manage infection prevention and control. ${ }^{27}$ The ODA submission again references the RCDSO when it reproduces guidance from 1999 that lists a scope of practice for dental assistants. The ODA states that the existence of this document means that a new scope of practice is not justified. This document is not available on the RCDSO website.

The final recommendation to the Minister of Health and Long Term Care from HPRAC was that dental assistants should not be regulated. The Minister accepted this recommendation. The HPRAC felt that it had not been presented with sufficient evidence to demonstrate a significant risk to the public were dental assistants to remain un-regulated. ${ }^{28}$

\section{South Africa}

The debate regarding the regulation of dental assistants in South Africa played out dramatically in 2015 when the South African Dental Association (SADA) challenged the ability of the Minister of Health to make regulations that establish and regulate a health profession. The matter played out in the Supreme Court of Appeal of South Africa in the resultant court case: South African Dental Association v
Minister of Health. ${ }^{29}$ The case was precipitated by the creation of regulations pertaining to: the required qualifications for registration as both student and fully-qualified dental assistants; the constitution of the Professional Board for Dental Therapy and Oral Hygiene; and regulations on the scope of practice of dental assistants. These were gradual evolutions of legislation from April 2005 to May 2012. The main cause for the action being brought by the SADA was a belief that the new regulations would lead to a great shortage of dental assistants in the country, that the traditional on-the-job training provided by employer dentists was adequate for the needs of the profession and that the Minister of Health had acted beyond his powers in promulgating these new regulations, especially given the SADA's strong objections throughout.

The respondents in the case were: the Minister of Health; the Health Professions Council of South Africa; the Chair of the Professional Board for Dental Therapy and Oral Hygiene; and the Dental Assistants Association of South Africa (DAASA). The DAASA were not originally involved directly in the litigation, but the Minister of Health was of the belief that their exclusion from the proceedings was tantamount to the exclusion of a necessary party. The DAASA had lobbied in earnest for the development of statutory recognition of dental assistants since 1995 . The SADA unsuccessfully tried to oppose the participation of the DAASA in the proceedings on the basis that it did not have the right to appear before the court on the issue. The SADA was heavily criticised by the Supreme Court of Appeal for its attitude, the majority stating: 'Throughout the litigation, SADA maintained a condescending and patronising attitude with regard to dental assistants, even adopting the contradictory, if not disingenuous, stance of claiming to act in their best interests while at the same time failing to cite the largest organisation representing that profession, and ultimately in fact going so far as to oppose their intervention as a party in the litigation. ${ }^{30}$ The DAASA stated that the SADA's objection to the regulation of dental assistants was more closely related to their own self-interest; the professionalisation of the dental assistant workforce was perceived to have negative, economic ramifications on the SADA membership, who had become used to the low wages paid to dental assistants. ${ }^{31}$ The SADA's behaviour towards the issue of dental assistant autonomy was shown to be inconsistent, with 
the organisation being demonstrated to be both in support and against the concept of professionalisation. This led the court to state that the SADA was, 'historically schizoid. ${ }^{32}$ Much of this case dealt with the internal politics of the dental profession; no convincing argument was put forward by the SADA that the regulation of dental assistants was unnecessary for the protection of the public.

\section{Moving forwards}

The arguments for and against the professionalisation of dental assistants have universal similarities regardless of jurisdiction. The debate in the UK following the publication of the report of the Dental Auxillaries Review Group in 1998 involved the same arguments ${ }^{33}$ that would be later made in both the Ontarian and South African consultations. Within Australia, both the Dental Assistants Professional Association Inc. and the Dental Assistants Association QLD Inc. state on their websites a common aim of seeking professional status and registration. In the South African case, the President of the HPCSA, Dr Kgosi Letlape, is reported to have been questioning of dentists' objections to the proposed professional registration of dental assistants. He stated: 'Part of the problem that we do not understand is why dentists would obstruct having their assistants being professionalised, so that they can get capable people, but meet a standard. But also so these people can have the pride of having this profession. ${ }^{34}$ It is both timely and in the public interest to consider how the Australian dental profession of the twenty-first century may utilise the most numerous member of the dental team for the effective prevention of oral disease. Their utilisation is likely to be most significant in clinical situations where it may not be practicable or economically viable to engage other dental professionals. Experiences from the UK show that dental assistants are professional and responsible members of the dental team, ${ }^{35}$ but that registration and the ability to develop additional skills must be followed-up with increased opportunities to put these into practice. ${ }^{36}$ In addition to the protection of the public, the creation of a more flexible workforce within health is one of the guiding objectives of the NRAS. We, the authors, strongly feel that the registration and appropriate regulation of dental assistants should become an integral strategy, both to protect the public and to help improve access to oral health services in Australia.

1. Health Practitioner Regulation National Law Act 2010 (ACT).

2. Health Practitioner Regulation National Law (NSW) [NSW].

3. Health Practitioner Regulation (National Uniform Legislation) Act [NT].

4. Health Practitioner Regulation National Law (South Australia) Act 2010 [SA].

5. Health Practitioner National Law (Tasmania) Act 2010 [TAS].

6. Health Practitioner Regulation National Law (Victoria) Act 2009 [VIC].

7. Health Practitioner Regulation National Law (WA) Act 2010 [WA].

8. Australian Government Job Outlook. Detal Assistants. Available at https://joboutlook.gov.au/occupation. aspx?code $=4232$ (accessed May 2018).

9. Queensland Industrial Relations Commission. Liquor Hospitality and Miscellaneous Union, Queensland Branch, Union of Employees v The Australian Dental Association (Queensland Branch) Union of Employers (B/2003/2082). 2005. Available at http://www.qirc.qld. gov.au/resources/word/qgig/2005/vol\%20180/no.4\%20 23.09.05/b2082[2003]dec.doc (accessed 23 May 2018).

10. Dental Practitioners Registration Act 2001. Available at https://www.legislation.qld.gov.au/view/pdf/2003-0328/act-2001-004 (accessed August 2018).

11. Gnich W, Deas L, Mackenzie S, Burns J, Conway D I. Extending dental nurses' duties: a national survey investigating skill-mix in Scotland's child oral health improvement programme (Childsmile). BMC Oral Health 2014; 14: 137

12. Blinkhorn F, Brown N, Freeman R, Humphris $G$, Martin A, Blinkhorn A. A phase II clinical trial of a dental health education programme delivered by aboriginal healthworkers to prevent early childhood caries. BMC Public Health 2012; 12: 681.

13. COAG Health Council. A National Code of Conduct FAQ. 2015. Available at http://www.coaghealthcouncil. gov.au/NationalCodeOfConductForHealthCareWorkers (accessed May 2018)

14. COAG Health Council. Final Report: A National Code of Conduct for health care workers. 2015. Available at http://www.coaghealthcouncil.gov.au/NationalCodeOfConductForHealthCareWorkers (accessed May 2018).

15. General Dental Council. Annual Report and Accounts 2016. 2017. Available at https://www.gdc-uk.org/ azindex (accessed May 2018).

16. Toulson $\mathrm{G}$. Dental nurse whose boss sparked biggest recall in NHS history is suspended indefinitely over poor hygiene practice. Nottingham Post. 2017. Available at https://www.nottinghampost.com/news/dental-nursewhose-boss-sparked-352334 (accessed May 2018)

17. General Dental Council. Hearing Heard in Public:Hague, Sally. 2015-2017. Available at https://gdcolrlive.blob. core.windows.net/annotationspublic/ce4c304a-bd81e711-8102-5065f38aea21 (accessed May 2018).

18. Corderoy A, Aubusson K. Sydney dentist scare: Hygiene breaches put 11,000 people at risk of HIV and hepatitis. The Sydney Morning Herald. 2015 Available at https:// www.smh.com.au/national/nsw/sydney-dentist-scarehygiene-breaches-put-11000-people-at-risk-of-hiv-andhepatitis-20150701-gi2r6h.html (accessed May 2018).

19. Olive R. Letter to the Deregulation Unit regarding Reducing Regulation in the Healthcare Portfolio. 2015 Available at https://www.ada.org.au/News-Media/ News-and-Release/Submissions/Reducing-regulationin-the-health-portfolio/30June15-Letter-to-DoH-reReducing-Reg (accessed May 2018).

20. Australian Health Minister's Advisory Council. Independ ent Review of the National Registration and Accreditation Scheme for health professions. 2014. Available at http://www.coaghealthcouncil.gov.au/Publications/ Reports/ArtMID/514/ArticleID/68/The-IndependentReview-of-the-National-Registration-and-AccreditationScheme-for-health-professionals (accessed May 2018).

21. Council of Australian Governments. Intergovernmental Agreement for a National Registration and Accreditation Scheme for the Health Professions. 2008. Information available at https://www.ahpra.gov.au/ (accessed May 2018).

22. Australian Bureau of Statistics. Patient Experiences in Australia: Summary of Findings, 2015-16. 2017. Available at http://www.abs.gov.au/AUSSTATS/abs@.nsf/ DetailsPage/4839.02015-16?0penDocument (accessed May 2018).

23. Regulated Health Professions Act 1991. Ontario.

24. Matthews D. Letter to the Chair of the Health Professions Regulatory Advisory Council. 2010. Available at http://www.hprac.org/en/resourcesGeneral/hprac-ministersletter.matthews.march26.10.MOLtrMarch2620101. pdf (accessed May 2018).

25. Ontario Dental Assistants Association. Submission for Regulation Under the Regulated Professions Act. 2011. Available at http://www.hprac.org/en/projects/ resources/DentalAssistantFormalApplicationforRegulation.pdf (accessed May 2018).

26. Health Professions Regulatory Advisory Council. Stakeholder Feedback on the Regulation of Dental Assistants under the Regulated Health Professionals Act, 1991 (RHPA) Responses from Organizations (1) 2012. Available at http://www.hprac.org/en/projects/resources/ Organizations1DA-Feb24A.pdf (accessed May 2018).

27. Royal College of Dental Surgeons of Ontario. Infection Prevention and Control in the Dental Office. 2010.

28. Health Professions Regulatory Advisory Council. The Health Profession Assistant: Consideration for the Dental Assistant Application for Regulation. 2013. Available at http://www.hprac.org/en/reports/currentreports.asp (accessed May 2018).

29. South African Dental Association v Minister of Health [2015] ZASCA 163.

30. South African Dental Association v Minister of Health [2015] ZASCA 163 [59]

31. Le Roux-Kemp A. The Making of a Health Profession: A South African Case Study. J Law Med 2017; 24: 707-721.

32. South African Dental Association v Minister of Health [2015] ZASCA 163 [32]

33. Grace M. DARG Report. Br Dent J 1999; 186: 101.

34. Bendile D. New dental assistant law met with mixed reaction. Eyewitness News. 2016. Available at https:// ewn.co.za/2016/02/10/New-dental-assistant-law-metwith-mixed-reaction (accessed May 2018).

35. Zhou Y, Forbes G M, Macpherson L M D, Ball G E, Humphris $G$ M. The behaviour of extended duties dental nurses and the acceptance of fluoride varnish application in preschool children. Br Dent J 2012; 213: 603-609.

36. Durkan C, Belsi A, Johnson R, Gallagher J. Career choice, pathways and continuing professional development of dental nurses at one institution. Br Dent J 2012; 213: E1. 